\title{
Outcomes of patients who underwent staged repair for pulmonary atresia with ventricular septal defects and major aorto-pulmonary collateral arteries at Southampton University Hospital, United Kingdom
}

\author{
M P B Goonetilleke ${ }^{1}$, G Veldman ${ }^{2}$ \\ Sri Lanka Journal of Child Health, 2014; 43(2): 84-87
}

\begin{abstract}
Objective: To assess the long-term outcomes of multistage surgical approach in 18 surviving patients in areas of mortality, requirement for postoperative interventional cardiac catheterization, saturations on air, right ventricular (RV) pressures in relation to the systemic pressures, RV and left ventricular (LV) functions and the adequacy of pulmonary arborisation.
\end{abstract}

Method: Data of all surviving patients who underwent complete repair at Southampton University Hospital were reviewed. Data were obtained using case notes and computer based patient records. No data were gathered by direct patient contacts. LV and RV ejection fractions were measured by cardiac magnetic resonance imaging. Pulmonary arborisation patterns were assessed using cardiac catheter data.

Results: A total of 26 patients had undergone complete repair. There were $8(30.8 \%)$ deaths and the 18 survivors constituted the study group. Eleven $(61.1 \%)$ had undergone three or more surgeries to attain complete repair. Fifteen $(83.3 \%)$ maintained resting saturations above $80 \%$ after surgery. Nine $(50 \%)$ had undergone three or more catheter interventions after complete repair. Eleven $(61.1 \%)$ had undergone one or more pulmonary ballooning. Nine $(50 \%)$ had undergone pulmonary artery (PA) stenting. Four (22.2\%) had a RV ejection fraction (EF) $<45 \%$ and $5(27.7 \%)$ had a LV EF $<45 \%$. Seven (38.8\%) had RV pressures $>50 \%$ of LV pressures. Certain zones of the lungs were significantly under-filled on complete repair.

Conclusions: Children with pulmonary atresia, ventricular septal defect and major aortopulmonary collaterals can be treated using a staged repair. There is a high mortality (31\%) with average functional results.

${ }^{1}$ Consultant Paediatric Cardiologist, Teaching
Hospital, Karapitiya, ${ }^{2}$ Consultant Paediatric
Cardiologist, Southampton University Hospital,
United Kingdom,

(Received on 18 July 2013: Accepted after revision on 30 August 2013)
(Key words: Pulmonary atresia; ventricular septal defect; major aorto-pulmonary collaterals)

\section{Introduction}

Pulmonary atresia with ventricular septal defect (VSD) and major aorto-pulmonary collateral arteries (MAPCAs) is an uncommon form of complex congenital heart disease with marked heterogeneity of pulmonary blood supply $1,2,3$. According to the natural history of this lesion, an estimated $65 \%$ of patients survive to 1 year of age and $50 \%$ to 2 years, regardless of surgical intervention ${ }^{1,2,3,4}$. Traditional management has involved staged unifocalization of pulmonary blood supply ${ }^{1,2,3}$. Until recently, the outcome for patients born with pulmonary atresia, VSD, and MAPCAs was extremely poor, with surgically treated patients having a probability of only $20 \%$ of being alive at age 30 years ${ }^{1,2,3,4,5}$. Moreover, there is little evidence that surgical management of these patients resulted in any improvement in their long term outcomes ${ }^{5,6}$.

Currently at Southampton General Hospital NHS Trust, children with this lesion are treated using a multi-staged repair approach. The operation involves preparatory procedures, consisting of aorto-pulmonary shunting and unifocalization of the MAPCAs with native pulmonary artery (PA) branches. When reasonable pulmonary vascularization has been obtained, the patients are treated with complete repair (CR) with transventricular closure of the VSD and right ventricular outflow tract reconstruction. The oldest living person was 26 years while the youngest was 2 years in this series.

\section{Objective}

The objective of this study was to assess the longterm outcomes of this multistage approach in 18 surviving patients with this condition. The main outcomes of interest were post surgical long term mortality, requirement for postoperative interventional cardiac catheterization, saturations on air, right ventricular (RV) pressures in relation to the systemic pressures, RV and left ventricular (LV) functions and the adequacy of pulmonary arborisation. 


\section{Method}

Eighteen patients who survived out of twenty six who were offered complete surgical repair constituted the study group. Complete repair was defined as refashioning the pulmonary vasculature by means of a Blalock Taussig (BT) shunt, unifocalisation of MAPCA's, construction of the right ventricular outflow tract with a RV to PA conduit and VSD closure. All patients were under the follow up of paediatric or Grown-up Congenital Heart $(\mathrm{GUCH})$ cardiologists at our institution at the time of the study.

The data of all surviving patients who underwent complete repair at Southampton University Hospital were reviewed. The data was obtained using case notes and computer based patient records. Radiological data such as the x-rays and cardiac magnetic resonance imaging (MRIs) were obtained using the GE PACS system. No data were gathered by direct patient contacts. Cardiac functions were assessed using the cardiac MRI. LV and RV ejection fractions (EF) measured by cardiac MRI (measurements were done by the cardiac radiologist) were used to assess the LV and RV function separately. Pulmonary arborisation patterns were assessed by an experienced paediatric cardiologist using the latest cardiac catheter data. Each lung was divided into three areas (upper, middle and lower zones). Antero-posterior and lateral catheter images were assessed and the results were recorded as satisfactory filling or under filling of each zone of the lung.

\section{Results}

The mortality according to the age groups is shown in table 1.

Table 1

Mortality according to the age groups

\begin{tabular}{|c|c|c|c|}
\hline Age group & Total & Alive & Dead \\
\hline <1year & 1 & 0 & 1 \\
\hline 1-5years & 6 & 3 & 3 \\
\hline 6-10years & 8 & 7 & 1 \\
\hline 11-18years & 4 & 3 & 2 \\
\hline$>$ 18years & 7 & 5 & $\mathbf{n = 8 ( 3 0 . 8 \% )}$ \\
\hline
\end{tabular}

Twenty six patients had undergone complete repair. Eighteen were alive at the time of this study with a mortality of $30.8 \%$. The resting saturations of the survivors are shown in Table 2.

Table 2

Resting saturations of the 18 survivors

\begin{tabular}{|c|c|c|c|}
\hline$>90 \%$ & $81-90 \%$ & $70-80 \%$ & $<70 \%$ \\
\hline 12 & 3 & 3 & 0 \\
\hline
\end{tabular}

Fifteen $(83.3 \%)$ maintained resting saturations above $80 \%$ according to the data. The number of surgeries performed on patients prior to complete repair are shown in Table 3

Table 3

No. of surgeries performed on patients prior to complete repair

\begin{tabular}{|c|c|}
\hline $\begin{array}{c}\text { No. of surgeries } \\
\text { performed }\end{array}$ & No. of live patients \\
\hline 1 & 2 \\
\hline 2 & 5 \\
\hline 3 & 3 \\
\hline 4 & 3 \\
\hline 5 & 3 \\
\hline 6 & 2 \\
\hline
\end{tabular}

Eleven $(61.1 \%)$ had undergone three or more surgeries at the time of reaching a complete repair. The number of catheter interventions done on patients after complete repair are shown in table 4 .

Table 4

Catheter interventions done on patients after complete repair

\begin{tabular}{|c|c|}
\hline $\begin{array}{c}\text { No. of catheter } \\
\text { interventions }\end{array}$ & Alive patients \\
\hline 1 & 4 \\
\hline 2 & 5 \\
\hline 3 & 3 \\
\hline 4 & 2 \\
\hline 5 & 2 \\
\hline 6 & 2 \\
\hline
\end{tabular}

Nine $(50 \%)$ had undergone three or more catheter interventions after attaining a complete repair. The number of pulmonary ballooning undergone by patients is shown in table 5 . 
Table 5

No. undergoing pulmonary ballooning

\begin{tabular}{|c|c|}
\hline $\begin{array}{c}\text { Pulmonary } \\
\text { artery ballooning }\end{array}$ & Alive patients \\
\hline 0 & 7 \\
\hline 1 & 4 \\
\hline 2 & 3 \\
\hline 3 & 2 \\
\hline 4 & 2 \\
\hline
\end{tabular}

Eleven (61.1\%) patients had undergone one or more pulmonary ballooning. The number of pulmonary artery stenting undergone by patients is shown in table 6 .

Table 6

No. undergoing pulmonary artery stenting

\begin{tabular}{|c|c|}
\hline $\begin{array}{c}\text { Pulmonary artery } \\
\text { stenting }\end{array}$ & Alive patients \\
\hline 0 & 9 \\
\hline 1 & 6 \\
\hline 2 & 3 \\
\hline
\end{tabular}

Nine $(50 \%)$ had undergone pulmonary artery stenting. The number of coil occlusions of MAPCAs undergone by patients is shown in table 7.
Table 7

No. of coil occlusions of MAPCAs

\begin{tabular}{|c|c|}
\hline $\begin{array}{c}\text { Coil occlusion of } \\
\text { MAPCA's }\end{array}$ & Alive patients \\
\hline 0 & 13 \\
\hline 1 & 3 \\
\hline 2 & 2 \\
\hline
\end{tabular}

Five $(27.7 \%)$ had undergone coil occlusion of MAPCA's. LV and RV ejection fraction assessment by cardiac MRI is shown in table 8 .

Table 8

LV and RV EF assessment by cardiac MRI

\begin{tabular}{|c|c|c|c|}
\hline \multicolumn{2}{|c|}{ RVEF } & \multicolumn{2}{c|}{ LVEF } \\
\hline$<45 \%$ & $>45 \%$ & $<45 \%$ & $>45 \%$ \\
\hline 4 & 14 & 5 & 13 \\
\hline
\end{tabular}

Four $(22.2 \%)$ had a RV EF $<45 \%$ and $5(27.7 \%)$ had a LV EF $<45 \%$. The RV pressures as a percentage of systolic blood pressure (SBP) is shown in table 9.

Table 9

$R V$ pressure as a percentage of $S B P$

\begin{tabular}{|c|c|}
\hline RV pressure & No. of cases \\
\hline$<50 \%$ of SBP & 11 \\
\hline $50-75 \%$ of SBP & 4 \\
\hline$>75 \%$ of SBP & 3 \\
\hline
\end{tabular}

Seven $(38.8 \%)$ were found to have RV pressures $>50 \%$ of LV pressures. The pulmonary arborisation patterns are shown in table 10 .

Table 10: Pulmonary arborisation patterns

\begin{tabular}{|l|c|c|c|c|c|c|}
\cline { 2 - 7 } \multicolumn{1}{c|}{} & \multicolumn{3}{c|}{ Right lung } & \multicolumn{3}{c|}{ Left lung } \\
\hline & Upper zone & Middle zone & Lower zone & Upper zone & Middle zone & Lower zone \\
\hline Adequate filling & 8 & 9 & 14 & 9 & 9 & 12 \\
\hline Under filling & 10 & 9 & 4 & 9 & 9 & 6 \\
\hline
\end{tabular}

The above table shows that certain zones of the lungs are significantly under filled since there are equal number of cases with under filling of these zones as against adequate filling. (Left upper, left middle and right middle zones)

\section{Discussion}

This study reports the experience with staged repair for the treatment of children with pulmonary atresia with VSD and MAPCAs. We evaluated long term mortality, saturations, need for postoperative interventional cardiac catheterization, RV pressures in relation to systemic pressures, $\mathrm{RV}$ and $\mathrm{LV}$ functions and pulmonary arborisation patterns.

Out of the total of 26 patients only 18 survived following a complete repair which means a mortality of $30.7 \%$. This is a significant mortality rate at a unit in a developed country with state of art facilities. This indicates the complexity of this condition and the high degree of surgical risk even in one of the best centres in the world. Therefore it will be a challenging task for developing countries like Sri Lanka with much less resources to undertake complex surgeries of this nature in the current era where the surgical waiting lists are quite long. This study has also shown that only $2(11 \%)$ of the live patients had undergone single stage complete repair whereas $16(89 \%)$ had needed multi staged repair. Eleven $(61 \%)$ had needed 3 or more surgeries when attaining complete repair. It is risky for a child to undergo complex multiple surgeries of this nature. The psychological stress which the child and the parents may undergo is 
enormous. Due to the complexity of this lesion the post surgical ICU and hospital stay is much longer than a simple cardiac lesion. Therefore these children will occupy ICU beds for longer duration and will certainly deprive children with completely correctable cardiac lesions awaiting surgery in a setting like ours with very limited resources.

Even after attaining complete repair 14 (78\%) had undergone two or more and $9(50 \%)$ three or more catheter based interventional procedures. This virtually means that the pain and suffering of the child is far from over despite attaining a complete repair after several complex surgical procedures.

The main objective of any cardiac surgery is to make the heart function optimally in order to live an active life. Ejection fraction (EF) of the ventricles measures the percentage of blood ejected from the ventricles in each systolic contraction and thus indicates the pumping ability of the heart. This study has shown that $5(28 \%)$ had a LV EF $<45 \%$ and $4(22 \%)$ had RV EF $<45 \%$. Cardiac functions can deteriorate each time when one undergoes bypass for cardiac surgery. Since attaining a complete repair of this condition needs multiple surgeries, it is not surprising to have such a high percentage of children with a low ventricular EF. Low EF invariably gives rise to poor effort tolerance and thus most of these children find it difficult to keep pace with their peers and this can cause additional stress.

One of the prime goals of surgical repair of this condition is to establish a near normal pulmonary circulation. In order to achieve this, the pulmonary vascular tree should be refashioned in such a way that its arborisation is uniform to all segments of the lung and the pulmonary artery (PA) pressures are kept at low levels. RV pressure is a good indicator of PA pressure. This study has shown that $7(39 \%)$ patients are having RV pressures $>50 \%$ of LV pressures. Thus, $39 \%$ of cases have pulmonary hypertension despite a complete repair. Pulmonary hypertension will cause further narrowing of the lumen of the pulmonary vasculature and ultimate pulmonary fibrosis thus further aggravating the PA pressures and compromising the pulmonary perfusion. To support this fact this study has revealed significant underperfusion of all three zones of both lungs in almost $50 \%$ of the cases. Compromised pulmonary perfusion ultimately gives rise to hypoxia and thus effort intolerance which will lead to a poor quality of life.

\section{Conclusions and recommendations}

Children with pulmonary atresia with VSD and MAPCAs can be treated using a staged repair and long-term survival into adulthood can be achieved with a multistage approach. In our experience, staged repair is associated with a relatively high mortality and average functional results querying feasibility of performing such complex surgeries in a limited resources setting. We anticipate future improvement in quality of life with reduced need for postoperative surgical and interventional catheterization in patients treated with this approach.

\section{References}

1. Rabinovitch M, Herrera-DeLeon V, Castaneda AR, Reid L. Growth and development of the pulmonary vascular bed in patients with tetralogy of Fallot with or without pulmonary atresia. Circulation 1981; 64:1234-49. http://dx.doi.org/10.1161/01.CIR.64.6.1234

2. Puga FJ, Leoni FE, Julsrud PR, Mair DD. Complete repair of pulmonary atresia, ventricular septal defect, and severe peripheral arborisation abnormalities of the central pulmonary arteries. Journal of Thoracic and Cardiovascular Surgery 1989; 98:1018-29.

3. Iyer KS, Mee RBB. Staged repair of pulmonary atresia with ventricular septal defect and major systemic to pulmonary artery collaterals. Annals of Thoracic Surgery 1991; 51:65-72. http://dx.doi.org/10.1016/00034975(91)90452-V

4. Jefferson K, Rees S, Somerville J. Systemic arterial supply to the lungs in pulmonary atresia and its relation to pulmonary artery development. British Heart Journal 1972; 34:418-27. http://dx.doi.org/10.1136/hrt.34.4.418

5. Haworth SG, Rees PG, Taylor JFN, Macartney FJ, de Leval M, Stark J. Pulmonary atresia with ventricular septal defect and major aortopulmonary collateral arteries: effect of systemic pulmonary anastomosis. British Heart Journal 1981; 45:133-41. http://dx.doi.org/10.1136/hrt.45.2.133

6. Ishibashi $\mathrm{N}$, Shin'oka $\mathrm{T}$, Ishiyama $\mathrm{M}$, Sakamoto T, Kurosawa H. Clinical results of staged repair with complete unifocalization for pulmonary atresia with ventricular septal defect and major aorto-pulmonary collateral arteries European Journal of Cardiothoracic Surgery 2007; 32(2): 202-8. http://dx.doi.org/10.1016/j.ejcts.2007.04.022 